\title{
TREND TERKINI PENGAJARAN BAHASA \\ DI PERGURUAN TINGGI: SATU ANALISIS
}

\author{
Zamri Mahamod \\ Fakulti Pendidikan, UKM \\ e-mail: d-zam@ukm.my
}

\begin{abstract}
This paper discusses the most current trend in language learning. It focuses on pedagogical content knowledge (PCK) which should be mastered by every langauge teachers. PCK refers to the knowledge of curriculum, curriculum content, teaching pedagogy, and students' characters. Language teachers need to consider considerable changes in language education especially dealing with educational curriculum and language teachers' trainings, language skills, the competence in teaching the suitable form and structure curriculum, teaching and learning strategies
\end{abstract}

\begin{abstract}
Abstrak: Kertas konsep ini membincangkan trend terkini dalam pengajaran bahasa. Fokus perbincangan menjurus kepada pengetahuan pedagogi kandungan (PPK) yang perlu dikuasai setiap guru bahasa. PPK meruju kepada pengetahuan kurikulum, pengetahuan isi kurikulum, pengetahuan pedagogi mengajar, dan pengetahuan tentang ciri-ciri murid. Guru bahasa perlu mengambil kira perubahan yang berlaku dalam pendidikan bahasa dari segi kurikulum pendidikan dan pelatihan guru-guru bahasa, kecakapan berbahasa, kemahiran mengajar, bentuk dan struktur kurikulum yang sesuai, strategi pengajaran dan pembelajaran serta bentuk penilaian dan pentaksiran yang sesuai dalam pendidikan bahasa. Trend terkini dalam pendidikan bahasa telah berubah. Guru-guru bahasa perlu berubah seiring dengan perubahan yang berlaku dalam sistem pendidikan masa kini di seluruh dunia.
\end{abstract}

Kata Kunci: Trend, pengajaran bahasa, perguruan tinggi

\section{PENGENALAN}

Transformasi dalam sistem pendidikan berlaku di kebanyakan negara, termasuklah di negara Malaysia dan negara jiran tetangga seperti Indonesia, Thailand, Filipina dan lain-lain. Penekanan kerajaan pusat terhadap peningkatan taraf pendidikan agar selari dengan kepesatan dunia teknologi maklumat dan dunia tanpa sepadan, maka setiap negara 'berlumba-lumba' memajukan sistem pendidikan kebangsaan masing-masing. Dalam hal ini, negara Malaysia melalui Kementerian Pelajaran Malaysia (KPM) dan Kementerian Pengajian Tinggi Malaysia (KPT) sentiasa mengambil berat akan kurikulum yang ditawarkan di setiap peringkat/jenjang pendidikan. Hal ini menunjukkan bahawa aspek pendidikan diberi perhatian dan penekanan agar modal insan yang bakal dibangunkan/dihasilkan dapat memacu negara Malaysia sebuah negara maju menjelang tahun 2020. Menurut Zamri, Jamalul Lail dan Mohammed Sani (2011), transformasi dan inovasi dalam sistem pendidikan di Malaysia sudah hampir mencapai taraf negara maju seperti Amerika Syarikat, United Kingdom dan Australia. Dalam beberapa aspek pendidikan, sistem pendidikan di Malaysia melebihi standard yang ditetapkan dalam sistem pendidikan di negara-negara maju. Hal ini terbukti melalui kemasukan ribuan penuntut asing yang belajar di pelbagai universiti awam dan swasta di Malaysia serta ranking dan rating universiti-universiti awam di Malaysia seperti UM, UKM, USM, UPM dan UTM yang diiktiraf antara 500 universiti terbaik di dunia.

\section{TREND TERKINI DALAM PENDIDIKAN BAHASA DALAM ABAD KE-21}

Masyarakat abad ke-21 merupakan masyarakat yang berorientasikan sains dan teknologi serta menggunakan prasarana teknologi maklumat terkini dalam kehidupan seharian (Juriah, Khalid, Raja Mohd Fauzi, Siti Fatimah, Nik Mohd Rahimi, Zamri \& Zarin 2001). Kemajuan sains dan teknologi ini turut menerima tempiasnya dalam sektor pendidikan. Sistem pendidikan di seluruh dunia telah banyak mengalami perubahan seiring dengan perkembangan teknologi maklumat dan dunia globalisasi ini. Sebagai contoh, perubahan-perubahan dalam pendidikan ini turut tercatat dalam banyak dasar yang dilaksanakan oleh kerajaan Malaysia seperti dalam rancangan Malaysia Ke-9 (RMK), Pelan 
Induk Pembangunan Pendidikan 2006-2010 (PIPP), Standard Guru Malaysia, dan lain-lain. Semua yang dihasratkan oleh KPM ini semuanya bermatlamat untuk melahirkan insan murid yang seimbang dan harmonis dari segi jasmani, emosi, rohani dan intelek (JERI) seperti yang terkandung dalam Falsafah Pendidikan Kebangsaan (KPM 1992).

Dalam menghasilkan guru bahasa yang dapat menangani dan mendepani pendidikan bahasa masa kini, penulis berpendapat empat aspek berikut perlu dikuasai oleh setiap guru bahasa. Penulis berdasarkan pendapat Shulman (1987) yang memperkenalkan empat konsep Pedagogical Content Knowledge atau Pengetahuan Pedagogi Kandungan (PPK) jika mahu menghasilkan guru yang cemerlang, berkesan, inovatif dan kreatif dalam pengajaran dan pembelajaran. Hal ini sewajarnya diikuti dan diamalkan oleh guru, termasuk guru-guru bahasa.

Shulman (1987) mendefinisikan PPK kepada pengetahuan guru menterjemahkan pengetahuan isi kandungan secara pedagogikal yang berkesan dengan memahami konteks dalam persekitaran pembelajaran di dalam bilik darjah berdasarkan pengetahuan guru terhadap pengetahuan isi kandungan subjek, pengetahuan pedagogi subjek, pengetahuan ciri setiap muridnya, pengetahuan tentang kepercayaan terhadap pendekatan pengajaran dan pembelajaran yang digunakan. PPK banyak melibatkan cara penyampaian guru secara berkesan terhadap sesuatu idea, analogi kukuh, ilustrasi menarik, contoh-contoh tepat dan munasabah, penerangan jelas dan bermakna serta tunjuk cara berkesan agar sesuatu isi pelajaran itu dapat difahami murid dengan mudah.

Dalam konteks trend terkini pendidikan bahasa, penggunaan PPK dapat memperkasa guru-guru bahasa. PPK dapat memperkasa pengajaran seseorang guru bahasa dari segi membimbing murid untuk memahami mata pelajaran bahasa dengan lebih bermakna seperti dengan penggunaan bahasa yang mudah difahami, pertuturan yang lancar dan sistematik, perwatakan yang ceria dan meyakinkan ketika kelas bahasa, penjelasan topik yang disusun, diolah, diubah suai dan disampaikan berdasarkan pelbagai kebolehan murid dan sebagainya. Dengan adanya PPK ini, guru-guru bahasa dapat menyampaikan isi pengajaran dengan lebih mudah dan berkesan.

\section{PENGETAHUAN KURIKULUM}

Pengetahuan kurikulum bermaksud guruguru bahasa perlu memahami, mengetahui dan menguasai bagaimana kurikulum bahasa itu dibina dan direka bentuk menjadi satu kurikulum yang sesuai untuk tahap kognitif murid. Antara elemen dalam pengetahuan kurikulum yang perlu ada dalam sesuatu kurikulum bahasa ialah:

- Kesinambungan kurikulum: Hal ini bermaksud setiap kurikulum Bahasa Melayu yang dibina perlu saling berkaitan antara satu sama lain. Sebagai contoh, kurikulum Bahasa Melayu menengah rendah ada kesinambungan dengan kurikulum Bahasa Melayu menengah atas. Tajuk tatabahasa misalnya, jika di peringkat sekolah rendah, penekanannya diberikan kepada tatabahasa yang mudah, pembinaan ayat-ayat yang mudah, maka sebaliknya di peringkat menengah rendah dan atas, sudah pasti tatabahasa yang digunakan jauh lebih sukar berbanding tatabahasa murid sekolah rendah. Begitu juga dengan pembinaan ayat dan sebagainya.

- Orientasi kurikulum: Penekanan kurikulum bahasa yang beroerintasikan peperiksaan perlu dikurangkan. Hal ini bermaksud, apabila kurikulum bahasa lebih berfokus kepada peperiksaan, maka matlamat utama untuk membantu murid menguasai kesemua kemahiran bahasa, kemahiran berkomunikasi dan lain-lain tidak tercapai. Murid hanya menguasai bahasa untuk tujuan peperiksaan sahaja.

- Pelaksanaan kurikulum: Guru-guru perlu memiliki pengetahuan bagaimana hendak melaksanakan pengajaran bahasa dengan menyeluruh untuk membolehkan guru-guru membuat perancangan dan pelaksanaan pengajarannya mengikut tahap perkembangan dan kematangan murid. Apabila guru bahasa memahami pelaksanaan kurikulum bahasa tersebut, maka guru-guru dapat merancang pelaksanaan kurikulum bahasa secara menyeluruh, terutamanya menangani perubahan-perubahan yang berlaku dalam pendidikan bahasa. Perkara ini penting diketahui dan dikuasai setiap guru agar pelaksanaan kurikulum bahasa yang dibuat dapat disesuaikan dengan keperluan dan tuntutan semasa seperti keperluan kemahiran abad ke-21.

- Kandungan sukatan pelajaran: Kandungan sukatan dalam mata pelajaran bahasa juga perlu berubah mengikut perubahan semasa 
yang berlaku. Perkara-perkara berkaitan dengan ICT, penilaian dan pentaksiran, kemahiran abad ke-21, kepelbagaian kecerdasan dan sebagainya perlu dimasukkan ke dalam sukatan pelajaran bahasa selain mengekalkan perkara-perkara sedia ada seperti kemahiran bahasa, penerapan nilai dan lain-lain. Sebaik-baiknya kesemua perkara ini disebatikan dalam sukatan pelajaran bahasa.

\section{PENGETAHUAN ISI KANDUNGAN}

Guru-guru bahasa perlu mempunyai tahap pengetahuan isi kandungan bahasa yang baik. Perkembangan terkini dalam kurikulum pendidikan bahasa sewajar diketahui dan diikuti oleh setiap guru bahasa. Antara pengetahuan isi kandungan bahasa yang perlu difokuskan ialah:

- Kesediaan guru bahasa untuk menyampaikan bahan pengajaran merupakan perkara terpenting dalam pengendalian sesi pengajaran dan pembelajaran. Hal ini bermakna pengetahuan seseorang guru bahasa tentang isi kandungan merupakan kesediaan terpenting untuk memastikan keberkesanan pengajarannya.

- Pengetahuan substantif, yaitu pengetahuan tentang apa yang ada dalam fakta atau konsep yang digunakan untuk menyusun idea dan maklumat tentang sesuatu tajuk dalam sesuatu mata pelajaran bahasa tersebut. Hal ini bermakna setiap guru bahasa seharusnya memiliki pengetahuan substantif ini, terutama bagi tajuk-tajuk yang melibatkan isu-isu semasa.

- Pengetahuan sintaktik, iaitu pengetahuan tentang cara bagaimana sesuatu perkara itu dibentuk dan dihasilkan berdasarkan prosedur, kaedah dan proses yang melaluinya, sesuatu kebenaran dan

- pengetahuan baru dapat dibina. Hal ini bermakna setiap guru bahasa perlu mengukuhkan kefahaman konseptual murid dengan menggunakan contoh, analogi, hujah secara logikal dan berhujah menggunakan asas fakta yang tepat mengikut tahap pemikiran murid.

- Penguasaan ilmu, yaitu setiap guru bahasa perlu menguasai ilmu tatabahasa dan ilmu pedagogi bahasa. Pengetahuan isi kandungan subjek yang berkaitan dengan sukatan, sama ada secara langsung atau tidak secara langsung merupakan faktor penentu kefahaman murid terhadap apa yang diajarkan oleh guru bahasa berkenaan. Hal ini bermakna tanpa menguasai ilmu bahasa, boleh mengganggu pemahaman dan pengetahuan murid tentang tajuk yang dipelajari.

Rumusannya, tahap keberkesanan pengajaran seseorang guru bahasa banyak bergantung kepada pengetahuan isi kandungan subjek dan kemampuan guru mengurus masa untuk dimanfaatkan sepenuhnya dalam pengajaran. Pengetahuan isi kandungan bahasa yang baik juga membantu guru merancang pengajaran harian, minggunan dan bulanan secara sistematik dan bertulis.

\section{PENGETAHUAN PEDAGOGI MENGAJAR}

Pengetahuan pedagogi mengajar bermaksud setiap guru perlu mempunyai pelbagai pengetahuan berkaitan pedagogi mengajar. Dalam konteks pendidikan bahasa, setiap guru bahasa sewajarnya memahami dan menguasai pelbagai kemahiran mengajar/ pedagogi terkini yang melibatkan kaedah, pendekatan, teknik dan strategi mengajar bahasa layu. Dalam pengajaran, seharusnya murid merasai dan dapat memahami bahawa guru bahasa mereka seharusnya lebih mahir dan lebih mengetahui sesuatu tajuk yang dibincangkan berbanding murid. Hal ini boleh dilihat antara lain melalui pedagogi mengajar yang guru gunakan, seperti Pendekatan pengajaran, kaedah pengajaran, teknik pengajaran dan, strategi pengajaran. Rajah 1 jelas memperlihatkan keempat- empat konsep tersebut sebenarnya berlaku serentak sewaktu menentukan sesuatu sesi pengajaran dan pembelajaran. Misalnya sewaktu mengajar, guru bahasa perlu menggunakan pendekatan daripada mudah kepada yang lebih sukar, atau daripada konkrit kepada abstrak. Hal ini kerana otak manusia berkembang secara berperingkat-peringkat. Oleh itu, adalah penting memperkenalkan perkara yang mudah-mudah kepada kanak-kanak terlebih dahulu sebelum mengajarkan konsep-konsep yang abstrak. 


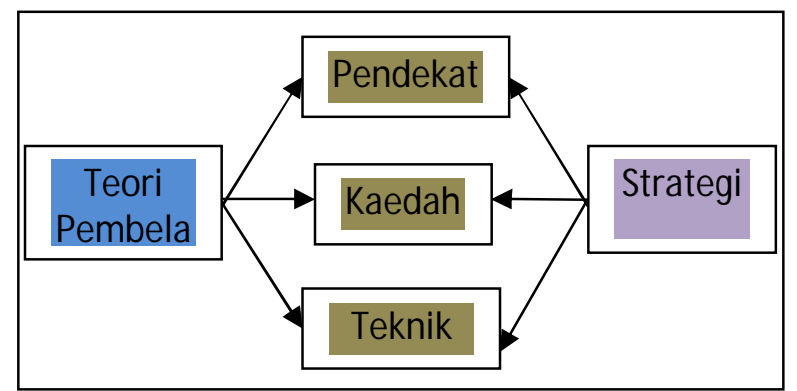

Skema 1. Perkaitan antara pendekatan, kaedah, teknik dan strategi dalam pengajaran dan pembelajaran

Kesimpulannya, dalam melaksanakan kepelbagaian kaedah pengajaran dan pembelajaran, guru bahasa perlu memilih kaedah yang sesuai digunakan seperti kaedah praktis, perbincangan, soal jawab dan sebagainya. Selepas kaedah yang hendak digunakan dipilih, barulah guru merancang teknik yang boleh komplemen dengan kaedah tersebut seperti teknik bercerita, latih tubi, menghafal dan seumpamanya. Usaha mengenal pasti dan memilih kaedah dan teknik yang sesuai dapat memenuhi pendekatan yang digunakan yang disebut sebagai strategi.

\section{KEMAHIRAN ABAD KE-21}

Dalam pengajaran dan pembelajaran bahasa, terdapat banyak kemahiran yang perlu dikuasai oleh murid (termasuk guru Bahasa Melayu). Seringkali terdapat kegagalan guru bahasa untuk menerapkan pelbagai kemahiran bahasa, terutamanya kemahiran-kemahiran abad ke-21. Murid-murid sepatutnya sudah boleh menyepadukan kemahiran-kemahiran abad ke-21 ketika mempelajari bahasa.

Dalam konteks kerja ini, saya ingin berkongsi pandangan tentang kemahiran-kemahiran abad ke-21 daripada perspektif enGauge Skill (NCREL \& Metiri Group 2003). Menurut kerangka kemahiran abad ke-21 en Gauge ini, terdapat empat komponen kemahiran abad ke-21 yang perlu dikuasai oleh murid dan juga guru. Dalam konteks pendidikan bahasa, guru-guru bahasa boleh memberi penekanan kemahirankemahiran abad ke-21 ini secara penyebatian dalam setiap tajuk dan kemahiran bahasa yang diajarnya. Kemahiran abad ke-21 ini dipaparkan dalam Rajah 2.

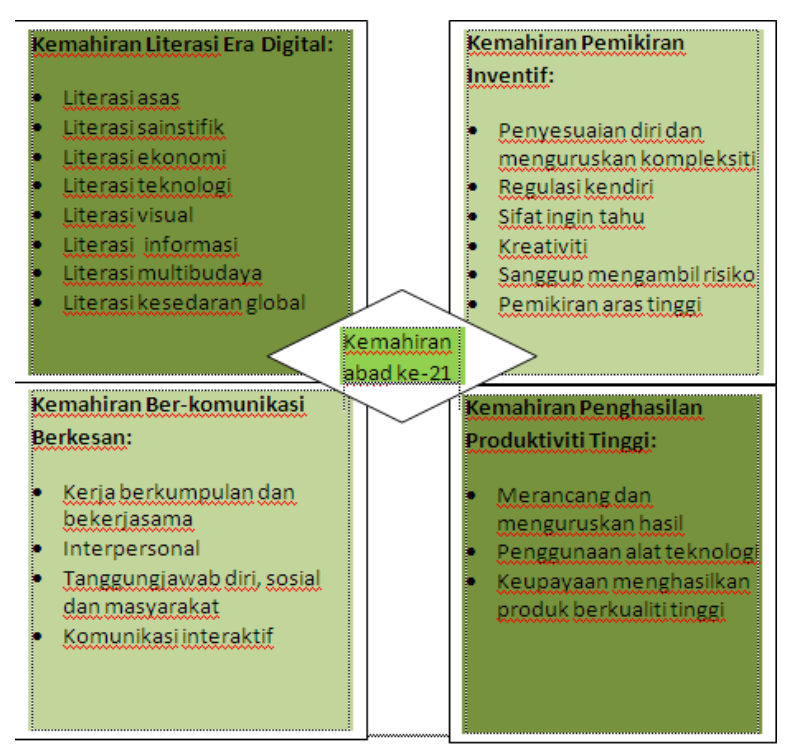

Skema 2. Kemahiran abad ke-21 en Guage

(Sumber: NCREL \& Metiri Group, 2003)

\section{LITERASI ERA DIGITAL}

Dalam era ICT ini, pengetahuan, kemahiran dan penguasaan ilmu tentang ICT amat penting bagi setiap guru bahasa. Oleh kerana ICT memberi impak perubahan yang amat besar dalam sistem pendidikan, maka peranan guru bahasa dalam menangani perubahan literasi era digital ini juga amat penting. Dalam hal ini, NCREL dan Metiri Group (2003) berpendapat bahawa penguasaan ilmu literasi era digital ini penting dikuasai oleh sesiapa sahaja, termasuk guru-guru bahasa.

\section{PEMIKIRAN INVENTIF}

Pemikiran inventif ialah satu aktiviti kognitif yang dapat membantu pengpalikasian kemahiran berfikir secara kreatif dan kritis di samping kemahiran menyelesaikan masalah melalui aktiviti inovasi dan reka cipta. Dalam konteks pendidikan bahasa, guru perlu memiliki pemikiran inventif jika inginkan mata pelajaran yang diajar menarik minat murid-muridnya.

\section{KOMUNIKASI BERKESAN/INTERAKSI}

Dalam konteks pendidikan bahasa, komunikasi berkesan amat ditekankan dalam proses pengajaran dan pembelajaran. Tanpa komunikasi yang berkesan, maka sesuatu perkara yang ingin disampaikan tidak dapat dilaksanakan dengan berjayanya. Misalnya, objektif pengajaran guru bahasa tidak tercapai apabila sesuatu tajuk yang diajar dalam satu jangka masa pengajaran tidak difahami oleh anak didiknya. Oleh itu, penguasaan komunikasi berkesan amat 
penting dalam pengajaran dan pembelajaran bahasa.

\section{PENGHASILAN PRODUKTIVITI TINGGI}

Kemahiran-kemahiran abad ke-21 antara lain bertujuan untuk melahirkan murid yang mampu mengaplikasikan segala kecanggihan ICT, mampu berfikir secara kritis dan kreatif, murid yang berdaya saing dan mempunyai sahsiah diri dan interpersonal yang tinggi.Dalam pendidikan bahasa, keupayaan dan pencapaian guru bukan sahaja diukur berdasarkan peratusan cemerlang (kuantiti) dalam peperiksaan, tetapi juga berdasarkan kualiti murid yang dihasilkan itu. Jika murid yang dihasilkannya itu berjaya menguasai pelbagai kemahiran dan pada masa yang sama mempunyai kelulusan dalam peperiksaan, maka guru berkenaan sudah berjaya menghasilkan produk yang bermutu tinggi, terutamanya dalam menghadapi cabaran kerjaya pada masa kini. Menurut Kellner (2000), murid yang kurang atau tidak memperoleh kemahirankemahiran abad ke-21, mereka akan menghadapi banyak saingan dalam kehidupan, erutamanya cabaran dalam dunia kerja. Oleh itu, penghasilan produktiviti tinggi dalam pendidikan bahasa juga harus diberi perhatian oleh setiap guru jika mahu berjaya dalam kerjaya masing-masing.

\section{NORMA, NILAI MURNI DAN KEROHANIAN}

Kemahiran abad ke-21 berkaitan dengan normal, nilai murni dan kerohanian ini bermaksud guru-guru bahasa perlu menerapkan elemen-elemen ini ketika mengajar bahasa. Penerapan dan penyebatian norma, nilai murni dan kerohanian ini tidak hanya diserapkan secara tersurat dalam kandungan kurikulum, tetapi juga secara tersirat. Menerapkan nilai rasa bersyukur mempelajari bahasa, mencintai bahasa ibunda serta menyedari akan kepentingan ilmu bahasa dalam kehidupan serta menyepadukan ilmu bahasa dengan pelbagai ilmu/multidisiplin/ merentas ilmu serta mengaitkan ilmu bahasa dengan ilmu dunia dan akhirat adalah penting dalam melahirkan murid yang memiliki kemahiran abad ke-21 yang seimbang dalam aspek norma, nilai murni dan kerohanian.

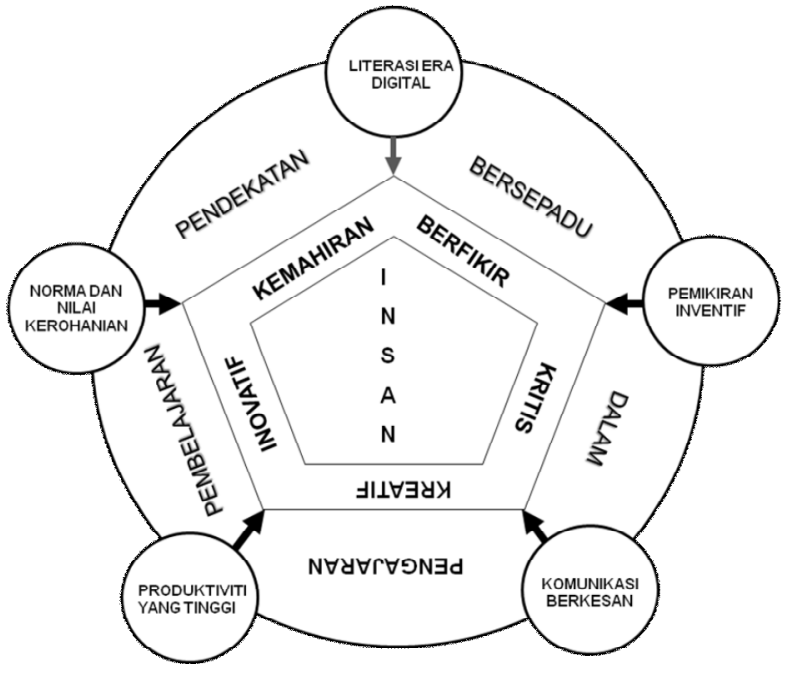

Rajah 4. Penerapan kemahiran abad ke-21 dalam pengajaran dan pembelajaran bahasa

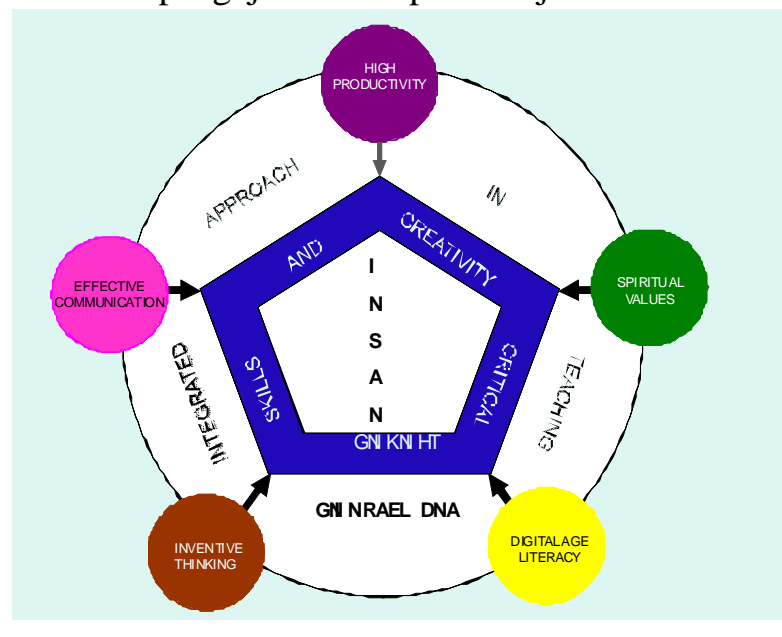

\section{CADANGAN PENAMBAHBAIKAN PENGAJARAN GURU BAHASA}

Seperti yang dibincangkan di atas, proses pengajaran dan pembelajaran bahasa perlu berubah seiring dengan kemajuan teknologi maklumat dan kemajuan dalam sistem pendidikan di seluruh dunia. Perubahanperubahan yang berlaku ini perlu diambil kira oleh guru bahasa jika inginkan pengajaran mereka sentiasa inovatif, menarik dan menyeronokkan. Berikut diberikan beberapa cadangan bagaimana hendak menambah baik pengajaran guru bahasa:

- Latihan dan pendidikan yang diterima oleh guru bahasa: Institusi yang bertanggungjawab melatih guru-guru bahasa perlu memastikan latihan dan pendidikan yang diterima oleh bakal-bakal guru ini memenuhi kriteria atau standard yang ditetapkan. Misalnya, kursus-kursus asas keguruan, kursus-kursus pengkhususan Bahasa Melayu, 
kursus-kursus elektif atau liberal, kursus kokurikulum memenuhi kriteria yang ditetapkan oleh sesuatu institusi penarafan seperti Malaysian Qualification Framework (MQA) di Malaysia.

- Kurikulum Bahasa: Sukatan Pelajaran Bahasa, Huraian Sukatan Pelajaran dan buku teks bahasa yang sedia ada perlu mengambil kira perkara-perkara seperti kepelbagaian murid, gaya dan strategi belajar, penyebatian dan penerapan nilai, kepelbagaian kaedah mengajar dan sebagainya. Kandungan kurikulum juga perlu lebih bermakna kepada murid (kontekstual) di samping memberi penekanan kepada keempat-empat kemahiran bahasa, pembelajaran berpusatkan murid, aplikasi ICT dan sebagainya.

- Pembangunan profesionalisme berterusan (Continuing professional development-CPD) guru Bahasa Melayu: Guru-guru bahasa hendaklah sentiasa dihantar mengikuti kursus, bengkel, seminar, galakkan membuat sangkutan (attachment), lawatan sambil belajar dan sebagainya sebagai satu kaedah peningkatan CPD guru-guru bahasa. Pendedahan berterusan CPD penting dalam melahirkan guru-guru bahasa yang sentiasa menerima idea-idea baru, kreatif dan inovatif yang dapat diaplikasikan dalam pengajaran dan pembelajaran di dalam bilik darjah.

- Penilaian dan pentaksiran pendidikan bahasa: Perlu kepada Pentaksiran Berasaskan Sekolah (yang telah dibincangkan) yang lebih bersifat menyeluruh, dan tidak terfokus kepada peperiksaan sahaja.

\section{SIMPULAN}

Al-Quran telah menjelaskan bahawa manusia itu diciptakan dengan berbagai-bagai tahap kemampuan akal, roh dan jasad (surah Ali'Imran 3:11, al-Am 6:165, al-Rum 30:22). Kepelbagaian yang wujud dalam kalangan manusia ini seharusnya difahami oleh setiap mereka yang terlibat secara langsung urusan dengan manusia. Guru-guru seharusnya memahami setiap muridnya adalah berbeza-beza tahap latar belakang sosioekonomi, budaya, bahasa dan agamanya, berbeza tahap kognitifnya, dan sebagainya. Apabila seseorang guru itu dapat memahami akan kewujudan kepelbagaian murid ini, maka guru-guru dapat merancang dan menentukan dengan baik proses pengajaran dan pembelajarannya (Wood 2002). Seseorang guru itu akan dapat memastikan pengajaran yang dijalankan secara bijaksana dengan mengambil kira tahap kemampuan pemikiran/kognitif serta kecenderungan murid supaya dapat menyemai keimanan, adat dan nilai yang benar serta menghapuskan adat dan amalan yang sesat secara berkesan (Zamri, Norasmah \& Mohammed Sani 2007).

Daripada perbincangan yang dirungkaikan dalam kertas kerja ini, ternyata pendidikan bahasa perlu dibuat transformasi dalam pelbagai perkara yang dibincangkan.Seharusnya guru-guru sebagai tonggak pendidikan negara berupaya memainkan peranan yang lebih aktif dalam memotivasikan diri mereka ke arah menjadi guru berkesan. Untuk menjadi guru berkesan, guruguru bahasa harus memiliki ilmu pedagogi dan keupayaan berkomunikasi dengan baik dan terkini. Guru-guru perlu berfikiran reflektif, kreatif dan inovatif. Guru-guru bahasa harus memainkan peranan sebagai constructivist leader yang mampu mencetuskan pemikiran murid. Peranan ini amat penting kerana guru bahasa akan membimbing dan memandu murid membuat pembelajaran sendiri melalui konsep selfpaced dan self-accessed. Amat penting seseorang guru bahasa itu mempunyai kebolehan merangsang pembelajaran kreatif dan kritis serta membina kemahiran berfikir dalam kalangan murid. Namun demikian, usaha ini tidak akan tercapai sekiranya tidak ada sokongan pelbagai pihak, daripada peringkat pengurusan, Kementerian Pelajaran, Pengetua/Kepala Sekolah, guru bahasa sehinggalah peranan murid, ibu bapa dan masyarakat dalam memastikan seseutaunmata muridan bahasa itu merupakan satu mata pelajaran yang amat seronok untuk belajar.

\section{DAFTAR RUJUKAN}

Arends, Richard I. 2001. Learning to Teach. Edisi Ke-5. Boston: Mc Graw-Hill.

Austin, H. \& Freebody, P. 2001. Assembling and Assessing the Child-Student: The Child as a Criterion of Assessment. Thousand Oaks: Sage Publication.

Grasha, A.F. 1996. Teaching with Styles: A Practical Guide to Enhance Learning by Understanding Learning and Teaching Styles. New York: Alliance Publisher.

Juliawati Ibrahim. 2006. Gaya Pengajaran Guru Bahasa Daerah Hulu Langat: Satu Kajian Tinjauan. Projek Sarjana Pendidikan. Fakulti Pendidikan, UKM Bangi. 
Juriah Long. 2010. Kaedah pengajaran dan pembelajaran Bahasa Melayu. (Pnyt.). Bangi: Penerbit UKM.

Kellner, D. 2000. New Technologies, new literacies: Reconstructing Education for the New Millennium. Teaching Education, 11 (3): 245-265.

Kementerian Pelajaran Malaysia. 1992. Falsafah Pendidikan Kebangsaan. Kuala Lumpur: KPM.

Kolb, D.A. 1976. Learning Style Inventory: SelfScoring Test and Interpretation Booklet. Boston, MA: McBer \& Co.

Mohammed Sani, Mohd Izham Mohd Hamzah \& Jainabee Kassim. 2008. Guru Berkesan. Bangi: Penerbit Fakulti Pendidikan, UKM.

Mohd Najib Tun Haji Abdul Razak. 1999. Majlis Sambutan Hari Guru Peringkat Kebangsaan Tahun 1997. Dewan Sukan Pahang, Kuantan. 16 Mei 1997. Dalam Koleksi Ucapan Menteri Pendidikan Malaysia 1995-1999.

Nor Razah Lim. 2007. Penggunaan Teknik Penyoalan lisan dalam kalangan guru Bahasa Melayu. Projek Sarjana Pendidikan. Fakulti Pendidikan, UKM Bangi.

Norlela Abdollah. 2007. Penyerapan Nilai-Nilai Murni dalam Pengajaran Bahasa Melayu. Projek Sarjana Pendidikan. Fakulti Pendidikan, UKM Bangi.

North Central Regional Educational Laboratory (NCREL) \& Metiri Group. 2003. EnGauge 21st century skills: Literacy in digital age. Los Angeles, CA: NCREL \& Metiri.

Ong Sze Chong. 2008. Hubungan Gaya Pembelajaran dengan Kecerdasan Emosi dan Pencapaian Akademik Mata Pelajaran Bahasa dalam Kalangan Murid Tingkatan 4. Projek Sarjana Pendidikan. Fakulti Pendidikan, UKM Bangi.

Partnership for $21^{\text {st }}$ Century Skills. 2008. $21^{\text {st }}$ Century Skills, Education and Competitiveness.

http://www.p21.org/documents/21st_centu ry_skill_education_and_competitiveness_g uide.pdf (18 April 2011).

Pusat Perkembangan Kurikulum. 1996. Kurikulum Abad ke-21: Kertas Konsep. Kuala Lumpur: KPM.

Ruslin Amir. 2007. Stail Berfikir, Stail Pengajaran dan Stail Pembelajaran
Pensyarah dan Murid, Universiti Kebangsaan Malaysia. Tesis Dr. Fal. Fakulti Pendidikan, UKM Bangi.

Suwarnee Mohd Solah. 2006. Persepsi Terhadap

Kesediaan dan Tahap Penggunaan

Teknologi Maklumat dan Komunikasi (TMK) dalam Kalangan Guru Bahasa Melayu di Sekolah Menengah Bandar dan Luar Bandar. Kertas Projek Sarjana Pendidikan. Fakulti Pendidikan, UKM Bangi.

Wood, J.W. 2002. Adapting Instruction to Accommodate Students in Inclusive Setting: Including all Students. New York: Pearson Education Inc.

Zamri Mahamod, Norasmah Othman \& Mohammed Sani Ibrahim. 2007. Profesionalisme Guru Novis: Model Latihan. Edisi Kedua. Bangi: Penerbit Fakulti Pendidikan, UKM.

Zamri Mahamod, Jamalul Lail Abdul Wahab \& Mohammed Sani Ibrahim. 2011. Transformasi dan Inovasi Dalam Pendidikan. Bangi: Penerbit Fakulti Pendidikan, UKM.

Zamri Mahamod, Mohamed Amin Embi \& Nik Mohd Rahimi Nik Yusoff. 2010. Strategi Pembelajaran Bahasa Melayu dan Inggeris Murid Cemerlang. Bangi: Penerbit Fakulti Pendidikan, UKM.

Zamri Mahamod, Mohamed Amin Embi \& Nik Mohd Rahimi Nik Yusoff. 2010. Pentaksiran Berasaskan Sekolah: Panduan untuk Guru Bahasa Melayu, Inggeris dan Arab. Bangi: Penerbit Fakulti Pendidikan, UKM.

Zamri Mahamod \& Mohamed Amin Embi. 2008. Teknologi Maklumat dan Komunikasi Dalam Pengajaran dan Pembelajaran Bahasa Melayu: Teori dan Praktis. (Pnyt.). Shah Alam: Karisma Publication.

Zamri Mahamod. 2004. Strategi Pembelajaran Bahasa Melayu dalam Kalangan Murid Cemerlang. Tesis Dr. Fal. Fakulti Pendidikan, UKM Bangi. 